\title{
Surface Modification of Austenitic Stainless Steel by means of Low Pressure Glow-Discharge Treatments with Nitrogen
}

\author{
Francesca Borgioli *, Emanuele Galvanetto and Tiberio Bacci \\ Department of Industrial Engineering, University of Florence, via S. Marta 3, 50139 Florence, Italy; \\ emanuele.galvanetto@unifi.it (E.G.); tiberio.bacci@unifi.it (T.B.) \\ * Correspondence: francesca.borgioli@unifi.it; Tel.: +39-055-275-8734
}

Received: 11 February 2019; Accepted: 4 March 2019; Published: 6 March 2019

\begin{abstract}
When low temperature nitriding of austenitic stainless steels is carried out, it is very important to remove the surface passive layer for obtaining homogeneous incorporation of nitrogen. In glow-discharge nitriding technique this surface activation is performed by cathodic sputtering pre-treatment, which can heat also the samples up to nitriding temperature. This preliminary study investigates the possibility of producing modified surface layers on austenitic stainless steels by performing low pressure glow-discharge treatments with nitrogen, similar to cathodic sputtering, so that surface activation, heating and nitrogen incorporation can occur in a single step having a short duration (up to about $10 \mathrm{~min}$ ). Depending on treatment parameters, it is possible to produce different types of modified surface layers. One type, similar to that obtained with low temperature nitriding, consists mainly of $\mathrm{S}$ phase and it shows improved surface hardness and corrosion resistance in $5 \% \mathrm{NaCl}$ solution in comparison with the untreated steel. Another type has large amounts of chromium nitride precipitates, which cause a marked hardness increase but a poor corrosion resistance. These surface treatments influence also water wetting properties, so that the apparent contact angle values become $>90^{\circ}$, indicating a hydrophobic behaviour.
\end{abstract}

Keywords: glow-discharge treatment; nitriding; austenitic stainless steels; AISI 202; S phase

\section{Introduction}

In the last few years low temperature nitriding has received increasing attention for the surface modification of austenitic stainless steels. When the treatments are performed at temperatures lower than $450^{\circ} \mathrm{C}$, the precipitation of large amounts of chromium nitrides is avoided and modified surface layers are produced, which consist mainly of a supersaturated interstitial solid solution of nitrogen in the expanded and distorted $\gamma$-Fe f.c.c. lattice, known as $S$ phase or expanded austenite [1,2]. Thanks to this phase, having high hardness (up to $1500 \mathrm{HV}$ [1]) and corrosion resistance, improvements of surface hardness, wear resistance and corrosion resistance in chloride-ion containing solutions are obtained [1,2]. Moreover, this surface modification influences also water wettability [3-5] and biocompatibility [4-6].

In order to allow a homogeneous incorporation of nitrogen during the treatment, the passive oxide film of stainless steels has to be previously removed. This surface activation is the first and fundamental step in the nitriding treatment, and it has been shown that the pre-cleaning procedure and parameters can also influence the modified layers thickness and growth [1,7]. The cathodic sputtering technique, which is usually used as the pre-treatment of plasma nitriding or ion implantation processes, is particularly efficient [7], and it allows both surface cleaning and heating of the samples up to the treatment temperature thanks to ion bombardment [8]. Pre-treatments using 
argon [9], hydrogen [7], argon-hydrogen [10], nitrogen [7], and nitrogen-hydrogen [8] were reported, often at pressures lower than $100 \mathrm{~Pa}$; the low pressures cause not only an enhancement of the sputtering effect but also a surface etching [3]. When nitrogen is used in the gas mixture, its incorporation in the surface layers may occur, depending on treatment parameters [11].

This preliminary study investigates the effects of low pressure glow-discharge treatments, performed with a nitrogen containing gas mixture, on the surface modification of AISI 202 austenitic stainless steel. These treatments can be considered similar to cathodic sputtering, since they activate the surface and heat the samples, but they also allow a significant nitrogen incorporation in a fairly short duration. Microstructure, phase composition, roughness, surface microhardness, water wetting and corrosion resistance of the treated samples were studied, and they were compared with those of samples untreated and subjected to nitriding treatment.

\section{Materials and Methods}

Samples $(40 \mathrm{~mm} \times 17 \mathrm{~mm} \times 0.7 \mathrm{~mm}$ ) of AISI 202 austenitic stainless steel were obtained from cold rolled, annealed and pickled plates by cutting, grinding and polishing up to $6-\mu \mathrm{m}$ diamond suspension. The chemical composition of the steel was (in wt.\%): $0.065 \mathrm{C}, 17.0 \mathrm{Cr}, 4.1 \mathrm{Ni}, 7.7 \mathrm{Mn}, 0.40$ $\mathrm{Si}, 0.15 \mathrm{~N}$. X-ray diffraction analysis showed that, besides austenite, a small amount of ferrite, $\alpha$-Fe (b.c.c.), was present in the steel.

Glow-discharge treatments were carried out in a laboratory plasma equipment, previously described [12]. The treatment temperature was controlled varying the discharge current supplied by a DC power supply and it was measured by a chromel-alumel thermocouple inserted into the sample holder. The low pressure treatments were performed at $130 \mathrm{~Pa}$ using a 80 vol. $\% \mathrm{~N}_{2}+20$ vol. $\% \mathrm{H}_{2}$ gas mixture in a $175 \mathrm{sccm}$ flow rate. As depicted in Figure 1, the discharge current density was fixed and increased with two constant steps, while the voltage drop between the electrodes and the treatment temperature were allowed to increase freely. At the beginning the current density was fixed at $2.2 \pm 0.1 \mathrm{~mA} \mathrm{~cm}^{-2}$; with these conditions the voltage drop between the electrodes increased from $245 \pm 5 \mathrm{~V}$ with a rate of about $35 \mathrm{~V} \mathrm{~min}^{-1}$ and the treatment temperature increased from room temperature $\left(23^{\circ} \mathrm{C}\right)$ with a rate of about $34^{\circ} \mathrm{C} \mathrm{min}^{-1}$. When the measured temperature reached $140{ }^{\circ} \mathrm{C}$, current density was increased and fixed at $2.6 \pm 0.1 \mathrm{~mA} \mathrm{~cm}^{-2}$; with these conditions the voltage drop increased with a rate changing from about 45 to about $65 \mathrm{~V} \mathrm{~min}^{-1}$ and the temperature with a rate of about $50{ }^{\circ} \mathrm{C} \mathrm{min}^{-1}$. When a prefixed voltage drop was reached, the power supply was turned off, the treatment chamber was evacuated and the samples were allowed to cool down to room temperature under vacuum. A set of samples (Type A) was treated up to a maximum voltage drop of $595 \pm 5 \mathrm{~V}$, reaching a measured bulk temperature of $330^{\circ} \mathrm{C}$; the duration of the treatment was $8 \mathrm{~min}$. Another set (Type B) was treated up to a maximum voltage drop of $730 \pm 5 \mathrm{~V}$, reaching a bulk temperature of $430^{\circ} \mathrm{C}$; the duration of the treatment was $10 \mathrm{~min}$. A further set of samples (Type C) was subjected to a pre-treatment with the procedure $\mathrm{A}$, then it was nitrided at $380{ }^{\circ} \mathrm{C}, 500 \mathrm{~Pa}$ for $5 \mathrm{~h}$ with a treatment atmosphere of $80 \mathrm{vol} . \% \mathrm{~N}_{2}$ and $20 \mathrm{vol} . \% \mathrm{H}_{2}$; during nitriding the current density was $1.6 \pm 0.1 \mathrm{~mA} \mathrm{~cm}^{-2}$ and voltage drop $150 \pm 10 \mathrm{~V}$.

The microstructure of the untreated and treated samples was examined by light and scanning electron microscopies. Cross-sections were obtained by cutting the samples and mounting them with glass-filled epoxy thermosetting resin. The microstructure of the modified layers and of the matrix was delineated using acetic glyceregia etchant $(3 \mathrm{~mL} \mathrm{HCl}, 2 \mathrm{~mL} \mathrm{HNO}, 2 \mathrm{~mL}$ acetic acid, 1 drop of glycerol).

Phases were identified using X-ray diffraction analysis ( $\mathrm{Cu} \mathrm{K} \alpha$ radiation) in Bragg-Brentano configuration (D8 Advance, Bruker AXS GmbH, Karlsruhe, Germany). A semi-quantitative evaluation of the alloy elements $(\mathrm{Fe}, \mathrm{Cr}, \mathrm{Ni}, \mathrm{Mo}, \mathrm{Mn}, \mathrm{Si}$ ) and of nitrogen present in the surface layers of the samples was performed by means of X-ray fluorescence (XRF) (ZSX Primus II, Rigaku, Tokyo, Japan) analysis.

Roughness evaluation was carried out with a stylus profilometer, using a 2- $\mu$ m radius stylus with a 1-mN contact force; the cut-off length was $0.25 \mathrm{~mm}$. Ten measurements were taken at different locations on each sample. The average surface roughness $R_{a}$ (arithmetical mean deviation of the 
roughness profile from the mean line), the maximum height of profile $R_{\mathrm{z}}$ (sum of the largest profile peak height and the largest profile valley depth within a sampling length, according to EN ISO 4287:2009 norm [13]) and the mean height of profile elements $R_{c}$ (mean value of the profile element heights within a sampling length) were recorded.

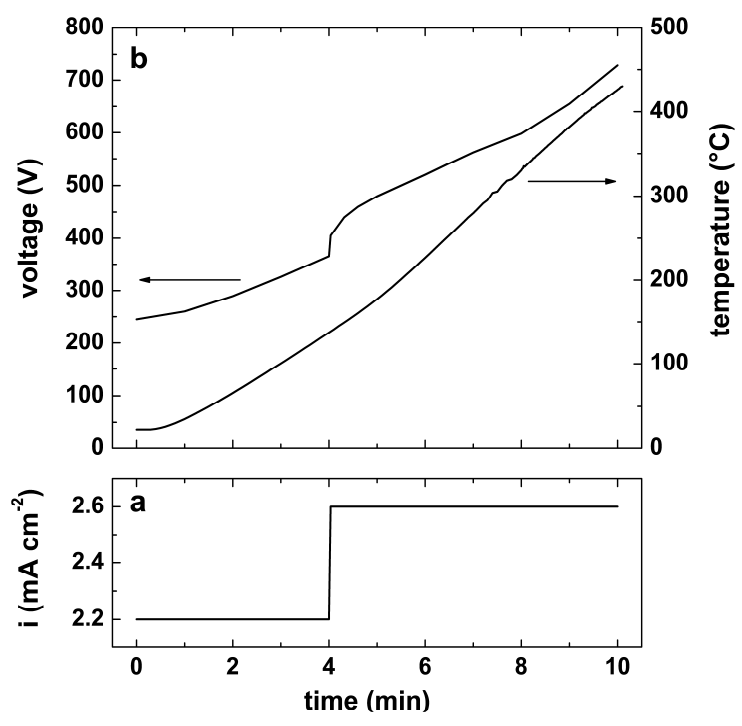

Figure 1. Current density (a), voltage drop and bulk temperature (b) as a function of time for Type-A and -B glow-discharge treatments. Type-A samples were treated up to $595 \pm 5 \mathrm{~V}$ (treatment duration: $8 \mathrm{~min}$ ); Type-B samples were treated up to $730 \pm 5 \mathrm{~V}$ (treatment duration: $10 \mathrm{~min}$ ).

The apparent static contact angle of water was measured according to the sessile drop method. Bi-distilled water was employed as test liquid, and drops of $0.5 \mu \mathrm{L}$ were used. Before the measurement, the samples were sonicated in acetone for $5 \mathrm{~min}$ and then freely dried in air. For each sample the contact angle was measured at least 10 times across the sample surface. All measurements were taken under ambient laboratory conditions. The contact angle values are given as the average value \pm standard deviation.

Surface microhardness measurements (load: 10 and $25 \mathrm{gf}$ ) were carried out on the samples using a Knoop indenter.

Corrosion behaviour was studied in $5 \% \mathrm{NaCl}$ aerated solution at room temperature by means of the potentiodynamic method. Polarization tests were performed using a standard three-electrode flat cell, equipped with an $\mathrm{Ag} / \mathrm{AgCl}$ reference electrode $(3.5 \mathrm{M} \mathrm{KCl}$ ) and a platinum grid as counterelectrode, after a delay of $18 \mathrm{~h}$ and with a potential scan rate of $0.3 \mathrm{mV} \mathrm{s}{ }^{-1}$. The sample surface area exposed to the electrolyte was $1 \mathrm{~cm}^{2}$. The degradation due to corrosion phenomena was evaluated also by means of coulometric analysis. Current density values of polarization curves were integrated from corrosion potential to $+1000 \mathrm{mV}(\mathrm{Ag} / \mathrm{AgCl})$, taking into account that:

$$
\text { potential }(\mathrm{mV}) / \mathrm{scan} \text { rate }\left(\mathrm{mV} \mathrm{s}^{-1}\right)=\text { time }(\mathrm{s})
$$

The integration was performed using the program Echem Analyst (Version 7.06, Gamry, Warminster, PA, USA).

\section{Results}

\subsection{Morphology and Microstructure}

After the treatment the surface of all sample types shows an etched appearance, which delineates grain boundaries with the characteristic twins. For Type-A samples, this etching, due to sputtering, is fairly low, and the grooves produced by the grinding and polishing procedure are still observable (Figure 2a). In some grains shear lines, due to local plastic deformation caused by nitrogen solubilization 
and the formation of modified layers, are observable. Surface roughness increases in comparison with untreated samples (Table 1). For Type-B samples, etching is more marked, especially at grain boundaries, and roughness markedly increases (Figure $2 b$ ). When the nitriding step is also performed (Type C), the surface shows the effects of both a strong etching, due to sputtering and nitriding, and local plastic deformations, owing to the formation of modified layers (Figure 2c), and roughness increase is marked.
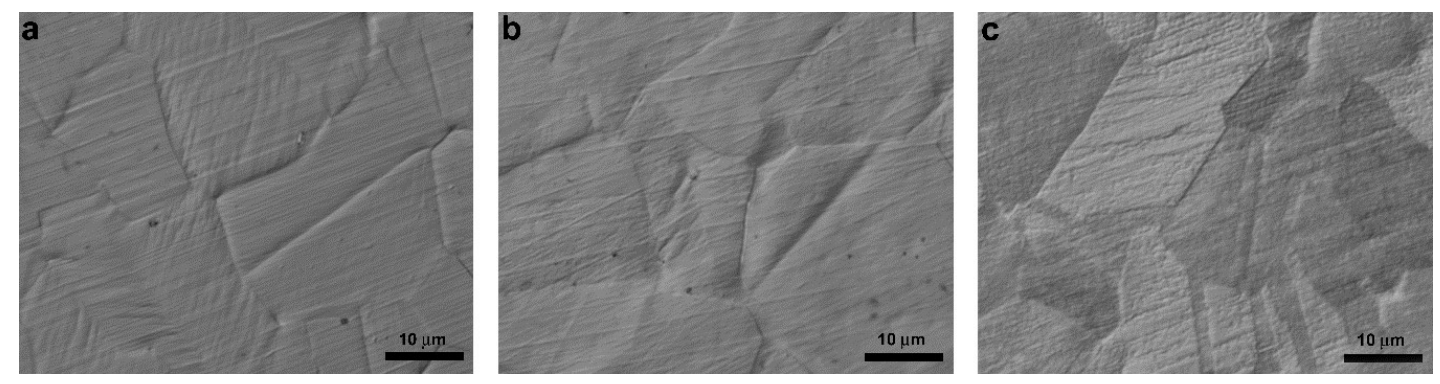

Figure 2. Surface morphology of Type-A (a), Type-B (b) and Type-C (c) treated samples.

Table 1. Roughness parameters $R_{\mathrm{a}}, R_{\mathrm{z}}$ and $R_{\mathrm{c}}$, for samples untreated and treated as indicated.

\begin{tabular}{cccc}
\hline Sample Type & $\boldsymbol{R}_{\mathbf{a}}(\boldsymbol{\mu m})$ & $\boldsymbol{R}_{\mathbf{z}}(\boldsymbol{\mu m})$ & $\boldsymbol{R}_{\mathbf{c}}(\boldsymbol{\mu m})$ \\
\hline untreated & $0.007 \pm 0.002$ & $0.046 \pm 0.008$ & $0.029 \pm 0.006$ \\
Type A & $0.011 \pm 0.002$ & $0.09 \pm 0.02$ & $0.06 \pm 0.01$ \\
Type B & $0.042 \pm 0.002$ & $0.32 \pm 0.04$ & $0.20 \pm 0.02$ \\
Type C & $0.045 \pm 0.005$ & $0.32 \pm 0.07$ & $0.21 \pm 0.05$ \\
\hline
\end{tabular}

The typical cross-section microstructure of the modified surface layers is shown in Figure 3, and X-ray diffraction patterns of untreated and treated samples are depicted in Figure 4. Type-A treatment produces modified surface layers, similar to those observed in low temperature nitrided AISI 202 stainless steel [12,14], with a thicker outer layer, in which S phase is present, and an inner layer consisting of a solid solution of interstitial atoms (nitrogen, carbon) in the slightly expanded austenite lattice, $\gamma(\mathrm{N}, \mathrm{C})$ (Figures $3 \mathrm{a}$ and $4 \mathrm{~b}$ ). The modified layers are fairly thin, having a thickness of $1.8 \pm 0.2 \mu \mathrm{m}$ as a whole. XRF analysis shows that, at the surface, a nitrogen content of about 22 at.\% is present.

When Type-B treatment is performed, the modified layers consist of a strongly etched outer layer and a fairly unetched inner layer (Figure 3b), having a thickness of $6.5 \pm 0.3 \mu \mathrm{m}$ as a whole. X-ray diffraction analysis shows that the phases present in the depth explored by X-ray beam are mainly $\mathrm{CrN}$ (f.c.c.) and $\alpha$-Fe (b.c.c.) (Figure 4c); small peaks ascribable to $\mathrm{S}$ phase are also observed. At the surface a nitrogen content of about 25 at.\% is detected, while the average chromium, nickel and manganese content does not significantly change when compared to that of the untreated samples.

The Type-C samples have the typical double layer microstructure of low temperature nitrided AISI 202 stainless steel [12,14], with an outer surface layer, in which many thin lines, related to plastic deformation, are observable (Figure 3c). In the outer layer $\mathrm{S}$ phase and a solid solution of nitrogen in h.c.p. martensite, $\varepsilon N^{\prime}$, are present, while in the inner layer $\gamma(\mathrm{N}, \mathrm{C})$ is detectable (Figure $4 \mathrm{~d}$ ). The modified layers have a thickness of $4.8 \pm 0.3 \mu \mathrm{m}$ as a whole. A nitrogen content of about 25 at. $\%$ is detected at the surface. 

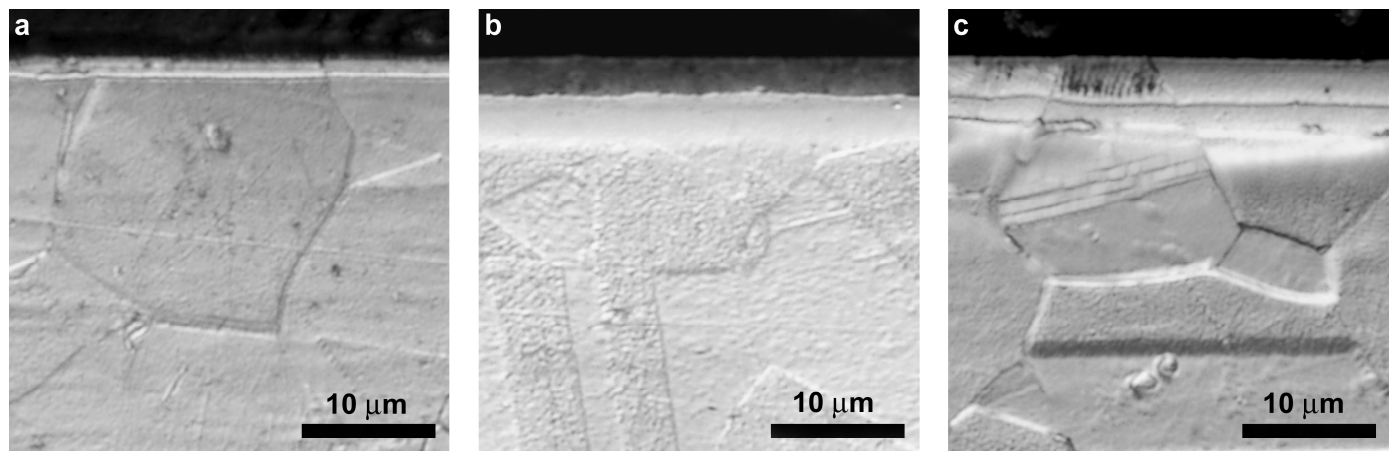

Figure 3. Micrographs of the modified surface layers of Type-A (a), Type-B (b) and Type-C (c) treated samples (etchant: acetic glyceregia).

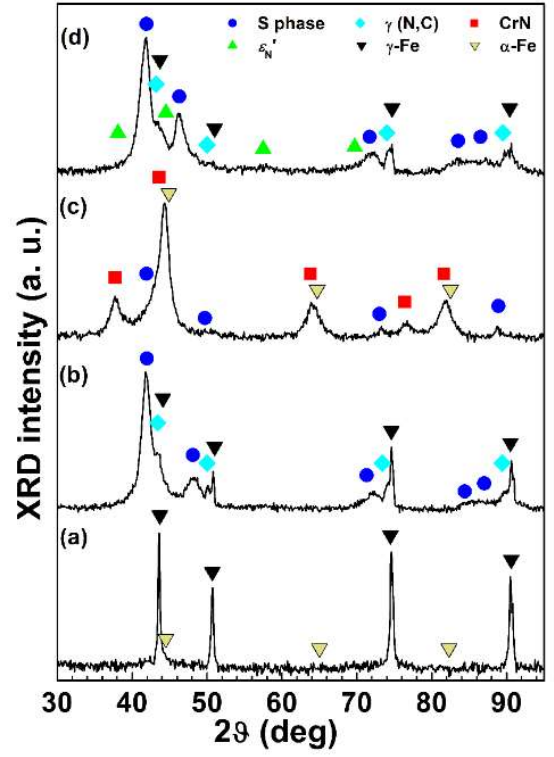

Figure 4. X-ray diffraction patterns of samples untreated (a) and Type-A (b), Type-B (c), and Type-C (d) treated.

\subsection{Water Contact Angle}

The apparent water contact angle values for untreated and treated samples are reported in Table 2. As an example, the images of drops on the surface of untreated and treated samples are shown in Figure 5. Untreated steel has a hydrophilic behaviour, but with a fairly large contact angle. After the treatment, for all the samples a significant increase of contact angle values is observed. For Type-A and Type-B samples the surface becomes hydrophobic, while for Type- $\mathrm{C}$ samples it remains hydrophilic, even if with large contact angle values.

a

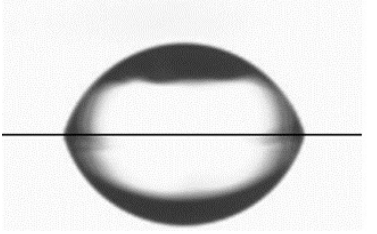

b

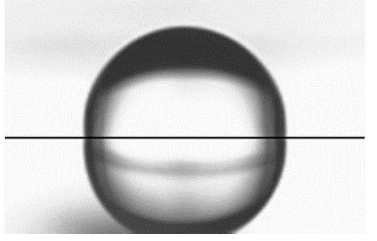

C

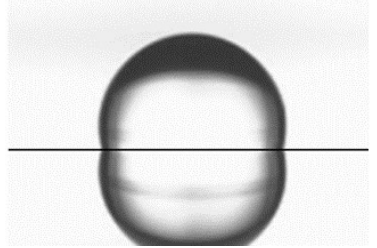

d

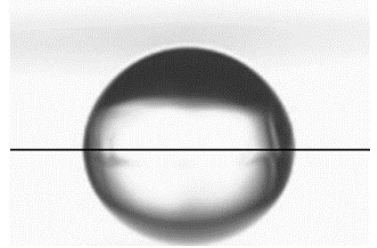

Figure 5. Images of $0.5-\mu \mathrm{L}$ drops deposited on the surface of samples untreated (a), and Type-A (b), Type-B (c) and Type-C (d) treated. The black line is drawn as a guide to the eye to outline the surface and to separate the drop from its reflection. 
Table 2. Apparent contact angle (CA) for samples untreated and treated as indicated.

\begin{tabular}{cc}
\hline Sample Type & CA $\left(^{\circ}\right)$ \\
\hline untreated & $73 \pm 3$ \\
Type A & $96 \pm 2$ \\
Type B & $104 \pm 2$ \\
Type C & $84 \pm 6$ \\
\hline
\end{tabular}

\subsection{Microhardness}

Surface microhardness values for untreated and treated samples are reported in Table 3. As the load is increased, lower hardness values are detected, due to both the indentation size effect and the fact that layers having different characteristics are tested.

All the treatments are able to significantly increase the surface microhardness in comparison with the untreated alloy. Type-A samples show only a moderate hardness increase, if compared with nitrided samples (Type C), owing to the smaller thickness of the modified layers. The hardness increase of Type-B samples is particularly marked, due to the presence of thick modified layers which are rich in hard nitride precipitates.

Table 3. Surface Knoop microhardness values of samples untreated and treated as indicated (test loads: 10 and $25 \mathrm{gf}$ ).

\begin{tabular}{ccc}
\hline Sample Type & HK $_{0.01}$ & HK $_{0.025}$ \\
\hline untreated & $339 \pm 11$ & $304 \pm 5$ \\
Type A & $903 \pm 32$ & $406 \pm 23$ \\
Type B & $1977 \pm 177$ & $1088 \pm 76$ \\
Type C & $1577 \pm 164$ & $795 \pm 22$ \\
\hline
\end{tabular}

\subsection{Corrosion Behaviour}

Typical polarization curves of untreated and treated samples are shown in Figure 6.

The untreated samples have a passive corrosion behaviour, with very low anodic current density values, which rapidly increase owing to the occurrence of localized corrosion phenomena when the potential is higher than about $+407 \mathrm{mV}(\mathrm{Ag} / \mathrm{AgCl})$. After the tests the surface of the samples shows many deep pits, randomly distributed on the surface. Crevice corrosion occurred in the area shielded by the PTFE gasket. The charge density value, obtained by integrating the anodic currents, is fairly high, $(1.9 \pm 0.1) \times 10^{5} \mathrm{mC} \mathrm{cm}^{-2}$, indicating a high level of damage.

The Type-A samples have a similar passive behaviour, but both corrosion and pitting potential values are significantly higher and anodic current density in the passive branch is lower, in comparison with those of untreated samples. After the tests, on the surface few shallow pits are present and a coloured region is observed in correspondence to part of the gasket. The lower damage, if compared to that produced on untreated samples, is evidenced also by smaller charge density, $(2.8 \pm 0.3) \times 10^{2} \mathrm{mC} \mathrm{cm}^{-2}$.

For Type-B samples an active corrosion behaviour is registered, with a low corrosion potential and a rapid increase of anodic current density values; the charge density is $(5.6 \pm 0.2) \times 10^{4} \mathrm{mC} \mathrm{cm}^{-2}$. After the tests, the surface of the samples is strongly coloured and many deep pits are present.

The Type-C samples have the typical behaviour of a low temperature nitrided austenitic stainless steel tested in $\mathrm{NaCl}$ solution. Corrosion potential is higher than that of the untreated steel, the passive branch is markedly wider and it has lower anodic current density. After the tests the surface of the samples shows only a small coloured region corresponding to part of the gasket, while the remaining area seems fairly untouched. The very low damage is evidenced also by the small charge density, $3 \pm 1 \mathrm{mC} \mathrm{cm}^{-2}$. 


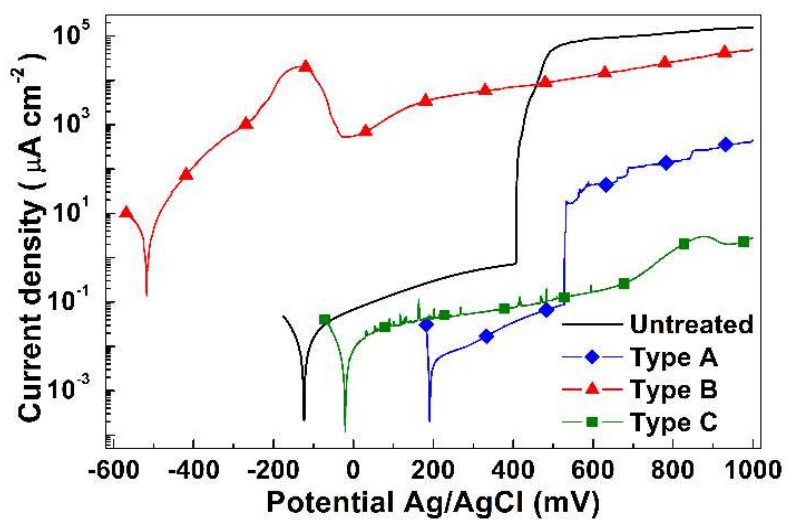

Figure 6. Polarization curves of samples untreated and treated as indicated (solution: $5 \% \mathrm{NaCl}$, aerated).

\section{Discussion}

The use of low pressure in glow-discharge treatments causes an increase of both the mean free path of molecules, atoms and ions present in plasma, and the discharge voltage between the electrodes. As a consequence, ion and fast neutral energy increases, so that sputtering rate becomes considerable [15] and etching is deep. The high ion energy can also increase the number of active nitrogen atoms [16], which are able to diffuse into the substrate if the nitrogen feeding is not completely counteracted by sputtering. Baranowska [11] and Baranowska et al. [17] reported a small nitrogen incorporation during cathodic sputtering, which can be explained with the low pressure of the treatment $(2-3 \mathrm{~Pa})$, causing a high sputtering rate. On the other hand, it was reported that nitriding treatments performed in the range 80-160 Pa allow a significant nitrogen incorporation $[3,16,18]$, suggesting that, in these conditions, nitrogen feeding is larger than sputtering.

The low pressure treatments reported in this study were performed using larger current densities and maximum voltage drop than those usually employed for nitriding [3,18], in order to have a fast heating of the samples. It may be supposed that, in these conditions, not only efficient surface activation and heating of the samples can occur, but also more active nitrogen atoms are obtained, which can diffuse into the substrate and produce modified surface layers in shorter times than those usually employed in nitriding treatments.

This preliminary study points out that the used low pressure treatments are very sensitive to process parameters, so that modified surface layers having significantly different characteristics can be obtained. When lower voltage drop and temperature are attained, as for Type-A treatment, the modified surface layers are similar to those produced by low temperature nitriding treatments having short durations $(1-3 \mathrm{~h})[14,19]$. By increasing the maximum voltage drop, and thus the maximum temperature, as for Type-B treatment, the modified surface layers are similar to those produced by nitriding at temperatures higher than $450^{\circ} \mathrm{C}[8,12]$. Large amount of $\mathrm{CrN}$ is able to form, and the loss of solubilised chromium from the matrix causes the subsequent transformation of f.c.c. austenite into b.c.c. $\alpha$-Fe $[20,21]$. It is interesting to note that $\mathrm{CrN}$ and $\alpha$-Fe formation occurs quickly, while iron based nitrides, $\gamma^{\prime}$-M4N (f.c.c.) and $\varepsilon-\mathrm{M}_{2-3} \mathrm{~N}$ (hex.) $(\mathrm{M}=\mathrm{Fe}, \mathrm{Mn}, \mathrm{Ni}, \mathrm{Cr})$, are not detected,

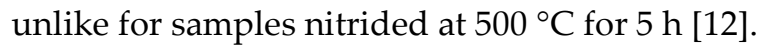

The increase of surface microhardness depends on the thickness of the modified layers and on the precipitation of hard nitrides, as previously reported $[8,12,14,18,19]$, so that a small increase is observed for Type-A samples while a larger one for Type-B samples.

A fairly large nitrogen solubilization and the formation of the $S$ phase improve the corrosion resistance of Type-A samples in $\mathrm{NaCl}$ solution, in comparison with the untreated steel. As previously observed [8,14,22], the beneficial effect of solubilized nitrogen allows to increase the corrosion potential and decrease anodic current density in the passive branch. For this sample type the increase of the potential, at which localized corrosion phenomena occur, is not as large as for the nitrided samples (Type C), but the level of damage is markedly lower if compared to that of untreated AISI 202 , as evidenced by the coulometric analysis. This fact may be ascribed to the lower nitrogen content 
and smaller thickness of the modified layers, in comparison with those of the nitrided samples $[14,22,23]$. On the other hand, in Type-B samples the presence of $\mathrm{CrN}$ precipitates causes a chromium depletion in the nearby regions, so that the formation of a protective passive film is prevented and a low corrosion resistance is observed, as registered also for samples nitrided at temperatures higher than $450^{\circ} \mathrm{C}[8,12,23,24]$.

For both Type-A and Type-B treatments the ion bombardment at the surface causes an etching, which is particularly marked at grain boundaries and it results stronger as the treatment is longer (Type B). Besides etching, surface morphology is affected also by the formation of modified layers, which causes local plastic deformations, as previously reported [3,8,14]. As a consequence, an increase of surface roughness is registered. The increase of the distance between peaks and valleys at the surface influences also water wettability. The increase of the apparent contact angle suggests that fakir drop lies on a composite surface of solid and air pockets trapped underneath, according to the Cassie-Baxter model $[25,26]$. This behaviour was observed also on low temperature glow-discharge nitrided samples [3]. The combination of strong etching at grain boundaries and limited plastic deformations inside the grains seems to promote the formation of many air pockets, so that a hydrophobic behaviour is observed. For the nitrided samples (Type C) larger plastic deformations occur at the surface, but the obtained results suggest that they are less efficient in producing air pockets if compared with low pressure treatments.

\section{Conclusions}

Modified surface layers can be produced, on AISI 202 austenitic stainless steel, by means of treatments performed with the glow-discharge technique at a pressure of $130 \mathrm{~Pa}$ in a $80 \mathrm{vol} . \% \mathrm{~N}_{2}$ and 20 vol.\% $\mathrm{H}_{2}$ gas mixture, so that surface activation, heating and nitrogen incorporation can occur in a single step having a short duration (up to $10 \mathrm{~min}$ ). Preliminary results show that the modified surface layers are very sensitive to treatment parameters. When lower voltage drop and temperature are attained, modified surface layers consisting mainly of $S$ phase form, and they have higher surface hardness and corrosion resistance in $5 \% \mathrm{NaCl}$ solution than the untreated alloy. These modified layers are similar to those produced by low temperature nitriding with short treatment durations (1-3 h). On the other hand, by increasing the maximum voltage drop, and thus the maximum treatment temperature, large amounts of $\mathrm{CrN}$ are able to form, so that a marked increase in surface hardness and a poor corrosion resistance are observed. Both treatment conditions produce an increase of surface roughness, which affects water wetting properties, causing a hydrophobic behaviour.

Author Contributions: Conceptualization, F.B., E.G., and T.B.; Software, E.G.; Formal Analysis, F.B. and E.G.; Investigation, F.B. and E.G.; Writing-Original Draft Preparation, F.B.; Writing-Review \& Editing, F.B. and E.G.; Supervision, F.B.; Project Administration, F.B.; Funding Acquisition, F.B. and T.B.

Funding: This research was funded by MIUR (Ministero dell'Istruzione, dell'Università e della Ricerca) (years 2014, 2015).

Acknowledgments: ThyssenKrupp Acciai Speciali Terni (Terni, Italy) is acknowledged for providing the AISI 202 steel.

Conflicts of Interest: The authors declare no conflict of interest.

\section{References}

1. Dong, H. S-phase surface engineering of Fe-Cr-Co-Cr and Ni-Cr alloys. Int. Mater. Rev. 2010, 55, 65-98.

2. Lo, K.H.; Shek, C.H.; Lai, J.K.L. Recent developments in stainless steels. Mater. Sci. Eng. R Rep. 2009, 65, 39104, doi:10.1016/j.mser.2009.03.001.

3. Borgioli, F.; Galvanetto, E.; Bacci, T. Influence of surface morphology and roughness on water wetting properties of low temperature nitrided austenitic stainless steels. Mater. Charact. 2014, 95, 278-284, doi:10.1016/j.matchar.2014.07.006.

4. Buhagiar, J.; Bell, T.; Simmons, R.; Dong, H. Evaluation of the biocompatibility of S-phase layers on medical grade austenitic stainless steels. J. Mater. Sci. Mater. Med. 2011, 22, 1269-1278. 
5. $\quad$ Lin, Y.-H.; Lan, W.-C.; Ou, K.-L.; Liu, C.-M.; Peng, P.-W. Hemocompatibility evaluation of plasma-nitrided austenitic stainless steels at low temperature. Surf. Coat. Technol. 2012, 206, 4785-4790.

6. Stio, M.; Martinesi, M.; Treves, C.; Borgioli, F. Cultures and co-cultures of human blood mononuclear cells and endothelial cells for the biocompatibility assessment of surface modified AISI 316L austenitic stainless steel. Mater. Sci. Eng. C 2016, 69, 1081-1091. doi:10.1016/j.msec.2016.08.010.

7. Baranowska, J. Importance of surface activation for nitrided layer formation on austenitic stainless steel. Surf. Eng. 2010, 26, 293-298. doi:10.1179/026708410X12550773058027.

8. Fossati, A.; Galvanetto, E.; Bacci, T.; Borgioli, F. Improvement of corrosion resistance of austenitic stainless steels by means of glow-discharge nitriding. Corros. Rev. 2011, 29, 209-221. doi:10.1515/CORRREV.2011.004.

9. Abrasonis, G.; Rivière, J.P.; Templier, C.; Muzard, S.; Pranevicius, L. Influence of surface preparation and ion flux on the nitriding efficiency of austenitic stainless steel. Surf. Coat. Technol. 2005, 196, 279-283. doi:10.1016/j.surfcoat.2004.08.109.

10. Czerwiec, T.; He, H.; Weber, S.; Dong, C.; Michel, H. On the occurrence of dual diffusion layers during plasma-assisted nitriding of austenitic stainless steel. Surf. Coat. Technol. 2006, 200, 5289-5295. doi:10.1016/j.surfcoat.2005.06.014.

11. Baranowska, J. Characteristic of the nitride layers on the stainless steel at low temperature. Surf. Coat. Technol. 2004, 180-181, 145-149. doi:10.1016/j.surfcoat.2003.10.056.

12. Borgioli, F.; Fossati, A.; Matassini, G.; Galvanetto, E.; Bacci, T. Low temperature glow-discharge nitriding of a low nickel austenitic stainless steel. Surf. Coat. Technol. 2010, 204, 3410-3417.

13. UNI EN ISO 4287:2009 Geometrical Product Specifications (GPS)-Surface Texture: Profile Method-Terms, Definitions and Surface Texture Parameters; UNI-Italian Organization for Standardization: Milan, Italy, 2009.

14. Borgioli, F.; Galvanetto, E.; Bacci, T. Corrosion behaviour of low temperature nitrided nickel-free, AISI 200 and AISI 300 series austenitic stainless steels in $\mathrm{NaCl}$ solution. Corros. Sci. 2018, 136, 352-365. doi:10.1016/j.corsci.2018.03.026.

15. Ruset, C.; Ciuca, S.; Grigore, E. The influence of the sputtering process on the constitution of the compound layers obtained by plasma nitriding. Surf. Coat. Technol. 2003, 174-175, 1201-1205.

16. Wang, S.; Cai, W.; Li, J.; Wei, W.; Hu, J. A novel rapid D.C. plasma nitriding at low gas pressure for 304 austenitic stainless steel. Mater. Lett. 2013, 105, 47-49. doi:10.1016/j.matlet.2013.04.031.

17. Baranowska, J.; Kusior, E.; Amigo, V.; Szczeciński, K. Surface modification of austenitic steel by lowtemperature plasma. Vacuum 2005, 78, 389-394. doi:10.1016/j.vacuum.2005.01.055.

18. Borgioli, F.; Fossati, A.; Galvanetto, E.; Bacci, T.; Pradelli, G. Glow discharge nitriding of AISI 316L austenitic stainless steel: Influence of treatment pressure. Surf. Coat. Technol. 2006, 200, 5505-5513.

19. Fossati, A.; Borgioli, F.; Galvanetto, E.; Bacci, T. Glow-discharge nitriding of AISI 316L austenitic stainless steel: influence of treatment time. Surf. Coat. Technol. 2006, 200, 3511-3517.

20. Collins, G.A.; Hutchings, R.; Short, K.T.; Tendys, J.; Li, X.; Samandi, M. Nitriding of austenitic stainless steel by plasma immersion ion implantation. Surf. Coat. Technol. 1995, 74-75, 417-424.

21. Menthe, E.; Rie, K.-T. Further investigation of the structure and properties of austenitic stainless steel after plasma nitriding. Surf. Coat. Technol. 1999, 116-119, 199-204. doi:10.1016/S0257-8972(99)00085-7.

22. Borgioli, F.; Fossati, A.; Raugei, L.; Galvanetto, E.; Bacci, T. Low temperature glow-discharge nitriding of stainless steels. In Proceedings of the 7th European Stainless Steel Conference-Science and Market, Como, Italy, 21-23 September 2011.

23. Fossati, A.; Borgioli, F.; Galvanetto, E.; Bacci, T. Corrosion resistance properties of glow-discharge nitrided AISI 316L austenitic stainless steel in $\mathrm{NaCl}$ solutions. Corros. Sci. 2006, 48, 1513-1527.

24. Bell, T. Surface engineering of austenitic stainless steel. Surf. Eng. 2002, 18, 415-422.

25. Cassie, A.B.D.; Baxter, S. Wettability of porous surfaces. Trans. Faraday Soc. 1944, 40, 546-550.

26. Quéré, D. Wetting and roughness. Ann. Rev. Mater. Res. 2008, 38, 71-99.

(C) 2019 by the authors. Licensee MDPI, Basel, Switzerland. This article is an open access article distributed under the terms and conditions of the Creative Commons Attribution (CC BY) license (http://creativecommons.org/licenses/by/4.0/). 